\title{
Computation of vertically averaged velocities in irregular sections of straight channels
}

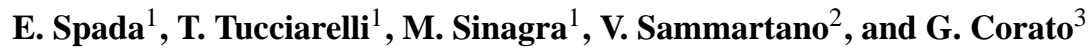 \\ ${ }^{1}$ Dipartimento di Ingegneria Civile, Ambientale, Aerospaziale, dei Materiali (DICAM), Università degli studi di Palermo, \\ Viale delle Scienze, 90128, Palermo, Italy \\ ${ }^{2}$ Dipartimento di Ingegneria Civile, dell'Energia, dell' Ambiente e dei Materiali (DICEAM), Università Mediterranea di \\ Reggio Calabria, Via Graziella, 89122, Reggio Calabria, Italy \\ ${ }^{3}$ Centre de Recherche Public - Gabriel Lippmann, 41 rue du Brill, 4422 Belvaux, Luxembourg \\ Correspondence to: E. Spada (eleonora.spada@unipa.it)
}

Received: 9 February 2015 - Published in Hydrol. Earth Syst. Sci. Discuss.: 27 February 2015

Revised: 27 August 2015 - Accepted: 28 August 2015 - Published: 14 September 2015

\begin{abstract}
Two new methods for vertically averaged velocity computation are presented, validated and compared with other available formulas. The first method derives from the well-known Huthoff algorithm, which is first shown to be dependent on the way the river cross section is discretized into several subsections. The second method assumes the vertically averaged longitudinal velocity to be a function only of the friction factor and of the so-called "local hydraulic radius", computed as the ratio between the integral of the elementary areas around a given vertical and the integral of the elementary solid boundaries around the same vertical. Both integrals are weighted with a linear shape function equal to zero at a distance from the integration variable which is proportional to the water depth according to an empirical coefficient $\beta$. Both formulas are validated against (1) laboratory experimental data, (2) discharge hydrographs measured in a real site, where the friction factor is estimated from an unsteady-state analysis of water levels recorded in two different river cross sections, and (3) the 3-D solution obtained using the commercial ANSYS CFX code, computing the steady-state uniform flow in a cross section of the Alzette River.
\end{abstract}

\section{Introduction}

Computation of vertically averaged velocities is the first step of two major calculations in 1-D shallow water modelling: (1) estimation of the discharge given the energy slope and the water stage and (2) estimation of the bottom shear stress for computing the bedload in a given river section.

Many popular software tools, like MIKE11 (MIKE11, 2009), compute the discharge $Q$, in each river section, as the sum of discharges computed in different subsections, assuming a single water stage for all of them. Similarly, HEC-RAS (HEC-RAS, 2010) calculates the conveyance of the cross section by the following form of Manning's equation:

$Q=K S_{f}^{1 / 2}$,

where $S_{f}$ is the energy slope and $K$ is the conveyance, computed assuming the same hypothesis and solving each subsection according to the traditional Manning equation.

The uniform flow formula almost universally applied in each subsection is still the Chezy equation (Herschel, 1897). The advantage of using the Chezy equation is that the associated Manning coefficient has been calibrated worldwide for several types of bed surface and a single value can be used for each application. However, it is well known that the Chezy equation was derived from laboratory measurements taken in channels with a regular, convex cross-sectional shape. When the section results from the union of different parts, each with a strongly different average water depth, one of two options is usually selected. The first option, called single channel method (SCM) is simply to ignore the problem. This leads to strong underestimation of the discharge, because the Chezy formula assumes a homogeneous vertically averaged velocity and this homogeneous value provides strong energy dissipation in the parts of the section with lower water depths. 
The second option, called divided channel method (DCM) is to compute the total discharge as the sum of the discharges flowing in each convex part of the section (called subsection), assuming a single water level for all parts (Chow, 1959; Shiono et al., 1999; Myers and Brennan, 1990). In this approach, the wet perimeter of each subsection is restricted to the component of the original one pertaining to the subsection, but the new components shared by each couple of subsections are neglected. This is equivalent to neglecting the shear stresses coming from the vortices with vertical axes (if subsections are divided by vertical lines) and considering additional resistance for higher velocities, which results in overestimation of discharge capacity (Lyness et al., 2001).

Knight and Hamed (1984) compared the accuracy of several subdivision methods for compound straight channels by including or excluding the vertical division line in the computation of the wetted perimeters of the main channel and the floodplains. However, their results show that conventional calculation methods result in larger errors. Wormleaton et al. (1982) and Wormleaton and Hadjipanos (1985) also discussed, in the case of compound sections, the horizontal division through the junction point between the main channel and the floodplains. Their studies show that these subdivision methods cannot assess well the discharge in compound channels.

The interaction phenomenon in compound channels has also been extensively studied by many other researchers (e.g. Sellin, 1964; Knight and Demetriou, 1983; Stephenson and Kolovopoulos, 1990; Rhodes and Knight, 1994; Bousmar and Zech, 1999; van Prooijen et al., 2005; Moreta and Martin-Vide, 2010). Their studies demonstrate that there is a large velocity difference between the main channel and the floodplain, especially at low relative depth, leading to a significant lateral momentum transfer. The studies by Knight and Hamed (1984) and Wormleaton et al. (1982) indicate that the vertical transfer of momentum between the upper and the lower main channels exists, causing significant horizontal shear able to dissipate a large part of the flow energy.

Furthermore, many authors have tried to quantify flow interaction among the subsections, at least in the case of compound but regular channels. To this end, turbulent stress was modelled through the Reynolds equations and coupled with the continuity equation (Shiono and Knight, 1991). This coupling leads to equations that can be analytically solved only under the assumption of negligible secondary flows. Approximated solutions can also be obtained, although they are based on some empirical parameters. Shiono and Knight developed the Shiono-Knight method (SKM) for prediction of lateral distribution of depth-averaged velocities and boundary shear stress in prismatic compound channels (Shiono and Knight, 1991; Knight and Shiono, 1996). The method can deal with all channel shapes that can be discretized into linear elements (Knight and Abril, 1996; Abril and Knight, 2004).

Other studies based on the Shiono and Knight method can be found in Liao and Knight (2007), Rameshwaran and Shiono (2007), Tang and Knight (2008) and Omran and Knight (2010). Apart from SKM, some other methods for analysing the conveyance capacity of compound channels have been proposed. For example, Ackers (1993) formulated the so-called empirical coherence method. Lambert and Sellin (1996) suggested a mixing length approach at the interface whereas, more recently, Cao et al. (2006) reformulated flow resistance through lateral integration using a simple and rational function of depth-averaged velocity. Bousmar and Zech (1999) considered the main channel/floodplain momentum transfer proportional to the product of the velocity gradient at the interface times the mass discharge exchanged through this interface due to turbulence. This method, called EDM (exchange divided method), also requires a geometrical exchange correction factor and turbulent exchange model coefficient for evaluating discharge.

A simplified version of the EDM, called interactive divided channel method (IDCM), was proposed by Huthoff et al. (2008). In IDCM, lateral momentum is considered negligible and turbulent stress at the interface is assumed to be proportional to the spanwise kinetic energy gradient through a dimensionless empirical parameter $\alpha$. IDCM has the strong advantage of using only two parameters, $\alpha$ and the friction factor, $f$. Nevertheless, as shown in the next section, $\alpha$ depends on the way the original section is divided.

An alternative approach could be to simulate the flow structure in its complexity by using a 3-D code for computational fluid dynamics (CFD). In these codes flow is represented both in terms of transport motion (mean flow) and turbulence by solving the Reynolds-averaged Navier Stokes (RANS) equations (Wilcox, 2006) coupled with turbulence models. These models allow for closure of the mathematical problem by adding a certain number of additional partial differential transport equations equal to the order of the model. In the field of the simulation of industrial and environmental laws, second-order models (e.g. $k-\varepsilon$ and $k-\omega$ models) are widely used. Nonetheless, CFD codes need a mesh fine enough to solve the boundary layer (Wilcox, 2006), resulting in a computational cost that can be prohibitive even for rivers of few kilometres in length.

In this study, two new methods aimed at representing subsection interactions in a compound channel are presented. The first method, named "integrated channel method" (INCM), derives from the Huthoff formula, which is shown to give results depending on the way the river cross section is discretized in subsections. The same dynamic balance adopted by Huthoff is written in differential form, but its diffusive term is weighted according to a $\xi$ coefficient proportional to the local water depth.

The second one, named "local hydraulic radius method" (LHRM), derives from the observation that, in the Manning formula, the mean velocity per unit energy gradient is proportional to a power of the hydraulic radius. It should then be possible to get the vertically averaged velocity along each vertical by using the same Manning formula, where the orig- 
inal hydraulic radius is changed with a "local" one. This "local" hydraulic radius should take into account the effect of the surrounding section geometry, up to a maximum distance which is likely to be proportional to the local water depth, according to an empirical $\beta$ coefficient. The method gives up the idea of solving the Reynolds equations, due to the uncertainty of its parameters, but relies on the solid grounds of the historical experience of the Manning equation.

The present paper is organized as follows: two of the most popular approaches adopted for computation of the vertically averaged velocities are explained in details along with the proposed INCM and LHRM methods. The $\xi$ and $\beta$ parameters of, respectively, the INCM and LHRM methods are then calibrated from available laboratory experimental discharge data and a sensitivity analysis is carried out. The INCM and LHRM methods are finally validated according to three different criteria. The first criterion is comparison with other series of the previous laboratory data not used for calibration. The second criterion is comparison with discharge data measured in one section of the Alzette River basin (Luxembourg). Because the friction factor is not known a priori, the INCM and LHRM formulas are applied in the context of the indirect discharge estimation method, which simultaneously estimates the friction factor and the discharge hydrograph from the unsteady-state water level analysis of two water level hydrographs measured in two different river sections. The third validation criterion is comparison with the vertical velocity profiles obtained by the ANSYS CFX solver in a cross section of the Alzette River. In the conclusions, it is finally shown that application of bedload formulas, carried out by integration of elementary solid fluxes computed as function of the vertically averaged velocities, can lead to results that are strongly different from those obtained by using the simple mean velocity and water depth section values.

\section{Divided channel method (DCM) and interactive divided channel method (IDCM)}

In the DCM method the river section is divided into subsections with uniform velocities and roughness (Chow, 1959). Division is made by vertical lines and no interaction between adjacent subsections is considered. Discharge is obtained by summing the contributions of each subsection, obtained by applying the Manning formula:

$q=\sum_{i} q_{i}=\sum_{i} \frac{R_{i}^{2 / 3} A_{i}}{n_{i}} \sqrt{S_{f_{i}}}$,

where $q$ is the total discharge, $A_{i}, R_{i}$ and $n_{i}$ are the area, the hydraulic radius and the Manning roughness coefficient of each sub section $i$ of a compound channel and $S_{f}$ is the energy slope, assumed constant across the river section. DCM is extensively applied in most of the commercial codes, two of them cited in the introduction.
In order to model the interaction between adjacent subsections of a compound section, the Reynolds and the continuity equations can be coupled (Shiono and Knight, 1991) to get

$\rho \frac{\partial}{\partial y}\left(H \bar{U}_{v} \bar{V}_{d}\right)=\rho g H S_{0}+\frac{\partial}{\partial y}\left(H \bar{\tau}_{x y}\right)-\tau_{b}\left(1+\frac{1}{s^{2}}\right)^{1 / 2}$,

where $\rho$ is the water density, $g$ is the gravity acceleration, $y$ is the abscissa according to the lateral direction, $U$ and $V$ are, respectively, the velocity components along the flow $x$ direction and the lateral $y$ direction, $H$ is the water depth, the subindex $d$ marks the vertically averaged quantities and the bar the time average along the turbulence period, $S_{0}$ is the bed slope, $s$ is the section lateral slope, and $\tau_{\beta}$ is the bed shear stress. The $\bar{\tau}_{x y}$ turbulent stress is given by the eddy viscosity equation, i.e.

$\bar{\tau}_{x y}=\rho \bar{\varepsilon}_{x y} \frac{\partial U_{d}}{\partial y}$,

$\bar{\varepsilon}_{x y}=\lambda U_{*} H$,

where the friction velocity $U_{*}$ is set equal to

$U_{*}=\left(\frac{f}{8 g}\right)^{1 / 2} U_{d}$,

and $f$ is the friction factor, depending on the bed material. The analytical solution of Eqs. (3)-(5) can be found only if the left-hand side of Eq. (3) is zero, which is equivalent to neglecting secondary flows. Other solutions can only be found by assuming a known $\Gamma$ value for the lateral derivative. Moreover, $\lambda$ is another experimental factor depending on the section geometry. The result is that the solution of Eq. (3) strongly depends on the choice of two coefficients, $\lambda$ and $\Gamma$, which are additional unknowns with respect to the friction factor $f$.

In order to reduce to one the number of empirical parameters (in addition to $f$ ) Huthoff et al. (2008) proposed the so-called interactive divided channel method (IDCM).

Integration of Eq. (3) over each $i$ th subsection, neglecting the averaged flow lateral momentum, leads to

$\rho g A_{i} S_{0}=\rho f_{i} P_{i} U_{i}^{2}+\tau_{i+1} H_{i+1}+\tau_{i} H_{i}$,

where the left-hand side of Eq. (6) is the gravitational force per unit length, proportional to the density of water $\rho$, to the gravity acceleration $g$, to the cross-sectional area $A_{i}$, and to the streamwise channel slope $S_{0}$. The terms on the right-hand side are the friction forces, proportional to the friction factor $f$ and to the wet solid boundary $P_{i}$, and the turbulent lateral momentum on the left and right sides, proportional to the turbulent stress $\tau$ and to the water depth $H$.

Turbulent stresses are modelled quite simply as

$\tau_{i+1}=\frac{1}{2} \rho \alpha\left(U_{i+1}^{2}-U_{i}^{2}\right)$, 
where $\alpha$ is a dimensionless interface coefficient, $U_{i}^{2}$ is the square of the vertically averaged velocity and $\tau_{i}$ is the turbulent stress along the plane between subsection $i-1$ and $i$. If subsection $i$ is the first (or the last) one, velocity $U_{i-1}$ (or $\left.U_{i+1}\right)$ is set equal to zero.

Following a wall-resistance approach (Chow, 1959), the friction factor $f_{i}$ is computed as

$f_{i}=\frac{g n_{i}^{2}}{R_{i}^{1 / 3}}$,

where $n_{i}$ is the Manning's roughness coefficient and $R_{i}$ (= $\left.A_{i} / P_{i}\right)$ is the hydraulic radius of subsection $i$.

Equations (6) forms a system with an order equal to the number $m$ of subsections, which is linear in the $U_{i}^{2}$ unknowns. The results are affected by the choice of the $\alpha$ coefficient equal to 0.02 , which is recommended by Huthoff et al. (2008), on the basis of lab experiments. Computation of the velocities $U_{i}$ makes it easy to estimate discharge $q$.

IDCM has the main advantage of using only two parameters, the $f$ and $\alpha$ coefficients. On the other hand, it can be easily shown that $\alpha$, although it is dimensionless, depends on the way the original section is divided. The reason is that the continuous form of Eq. (6) is given by

$\rho g\left(H S_{0}-\frac{f U^{2}}{g \cos \theta}\right)=\frac{\partial}{\partial y}(\tau H)$,

where $\theta$ is the bed slope in the lateral direction. Following the same approach as the IDCM, if we assume the turbulent stress $\tau$ to be proportional to both the velocity gradient in the lateral direction and to the velocity itself, we can write the right-hand side of Eq. (9) in the form

$\frac{\partial}{\partial y}(\tau H)=\frac{\partial}{\partial y}\left(\frac{\alpha_{H}}{2} \rho U \frac{\partial U}{\partial y} H\right)$,

and Eq. (9) becomes

$\rho\left(g H S_{0}-\frac{f U^{2}}{g \cos \theta}\right)=\frac{\partial}{\partial y}\left(H \frac{\partial}{\partial y}\left(\alpha_{H} \rho U^{2}\right)\right)$.

In Eq. (10) $\alpha_{H}$ is no longer dimensionless, but is a length. To get the same Huthoff formula from numerical discretization of Eq. (10), we should set

$\alpha_{H}=0.02 \Delta y$,

where $\Delta y$ is the subsection width, i.e. the integration step size. This implies that the solution of Eq. (11), according to the Huthoff formula, depends on the way the equation is discretized and the turbulence stress term on the right-hand side vanishes along with the integration step size.

\section{The new methods}

\subsection{Integrated channel method (INCM)}

INCM derives from the IDCM idea of evaluating the turbulent stresses as proportional to the gradient of the squared averaged velocities, leading to Eqs. (7) and (11). Observe that the dimensionless coefficient $\alpha$, in the stress computation given by Eq. (7), can be written as the ratio between $\alpha_{H}$ and the distance between verticals $i$ and $i+1$. For this reason, coefficient $\alpha_{H}$ can be thought of as a sort of mixing length, related to the scale of the vortices with horizontal axes. INCM assumes the optimal $\alpha_{H}$ to be proportional to the local water depth, because water depth is at least an upper limit for this scale, and the following relationship is applied:

$\alpha_{H}=\xi H$,

where $\xi$ is an empirical coefficient to be further estimated.

\subsection{Local hydraulic radius method (LHRM)}

LHRM derives from the observation that, in the Manning equation, the average velocity is set equal to

$V=\frac{R^{2 / 3}}{n} \sqrt{S_{0}}$

and has a one-to-one relationship with the hydraulic radius. In this context the hydraulic radius has the meaning of a global parameter, measuring the interactions of the particles along all the section as the ratio between an area and a length. The inconvenience is that, according to Eq. (14), the vertically averaged velocities in points very far from each other remain linked anyway, because the infinitesimal area and the infinitesimal length around two verticals are summed to the numerator and to the denominator of the hydraulic radius independently from the distance between the two verticals. To avoid this, LHRM computes the discharge as an integral of the vertically averaged velocities in the following form:

$q=\int_{0}^{L} h(y) U(y) \mathrm{d} y$,

where $U$ is set equal to

$U=\frac{\Re_{1}^{2 / 3}}{n} \sqrt{S_{0}}$,

and $\Re_{1}$ is defined as local hydraulic radius, computed as

$\Re_{1}(y)=\frac{\int_{a}^{b} h(s) N(y, s) \mathrm{d} s}{\int_{a}^{b} N(y, s) \sqrt{\mathrm{d} s^{2}+\mathrm{d} z^{2}}}$,
$a=\max (0, y-\beta h)$,
$b=\min (L, y+\beta h)$,

where $z$ is the topographic elevation (function of $s$ ), $\beta$ is an empirical coefficient and $L$ is the section's top width. Moreover $N(y, s)$ is a shape function where

$N(y, s)=\left\{\begin{array}{cl}-\frac{[y-\beta h(y)]-s}{\beta h(y)} & \text { if } a<s<y, \\ \frac{[y-\beta h(y)]-s}{\beta h(y)} & \text { if } b>s>y, \\ 0 & \text { otherwise. }\end{array}\right.$ 
Equation (18) shows how the influence of the section geometry, far from the abscissa $y$, continuously decreases up to a maximum distance, which is proportional to the water depth according to an empirical positive coefficient $\beta$. After numerical discretization, Eqs. (15)-(17) can be solved to get the unknown $q$, as well as the vertically averaged velocities in each subsection. If $\beta$ is close to zero and the size of each subsection is common for both formulas, LHRM is equivalent to DCM; if $\beta$ is very large, LHRM is equivalent to the traditional Manning formula. In the following, $\beta$ is calibrated using experimental data available in the literature. A sensitivity analysis is also carried out to show that the estimated discharge is only weakly dependent on the choice of the $\beta$ coefficient, far from its possible extreme values.

\subsection{Evaluation of the $\xi$ and $\beta$ parameters by means of lab experimental data}

INCM and LHRM parameters were calibrated by using data selected from six series of experiments run at the largescale Flood Channel Facility (FCF) of HR Wallingford (UK) (Knight and Sellin, 1987; Shiono and Knight, 1991; Ackers, 1993), as well as from four series of experiments run in the small-scale experimental apparatus of the Civil Engineering Department at the University of Birmingham (Knight and Demetriou, 1983). The FCF series were named F1, F2, F3, F6, F8 and F10; the Knight and Demetriou series were named K1, K2, K3 and K4. Series F1, F2, and F3 covered different floodplain widths, while series F2, F8, and F10 kept the floodplain widths constant but covered different main channel side slopes. Series F2 and F6 provided a comparison between the symmetric case of two floodplains and the asymmetric case of a single floodplain. All the experiments of Knight and Demetriou (1983) were run with a vertical main channel wall but with different $B / b$ ratios. The series $\mathrm{K} 1$ has $B / b=1$ and its section is simply rectangular. The $B / b$ ratio, for Knight's experimental apparatus, was varied by adding an adjustable side wall to each of the floodplains either in pairs or singly to obtain a symmetrical or asymmetrical cross section. The geometric and hydraulic parameters are shown in Table 1; all notations of the parameters can be found in Fig. 1 and $S_{0}$ is the bed slope. The subscripts $\mathrm{mc}$ and fp of the side slope refer to the main channel and floodplain, respectively. Perspex was used for both main flume and floodplains in all tests. The related Manning roughness is $0.01 \mathrm{~m}^{-1 / 3} \mathrm{~s}$.

The experiments were run with several channel configurations, differing mainly for floodplain geometry (widths and side slopes) and main channel side slopes (see Table 1). The $\mathrm{K}$ series were characterized by vertical main channel walls. More information concerning the experimental setup can be found in Table 1 (Knight and Demetriou, 1983; Knight and Sellin, 1987; Shiono and Knight, 1991).

Four series, named F1, F2, F3 and F6, were selected for calibration of the $\beta$ coefficient using the Nash-Sutcliffe (NS)

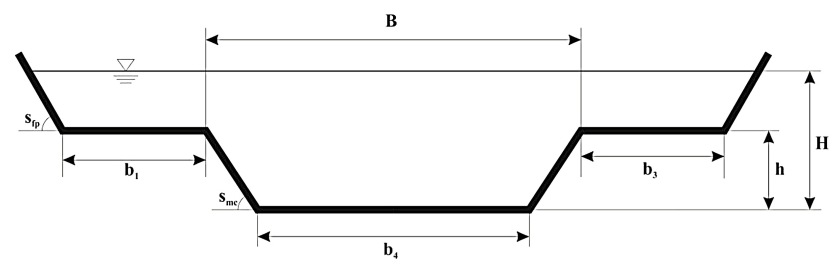

Figure 1. Geometric parameters of a compound channel.

Table 1. Geometric and hydraulic laboratory parameters of the experiment series.

\begin{tabular}{lcccccccc}
\hline Series & $\begin{array}{c}S_{0} \\
{[\%,}\end{array}$ & $\begin{array}{c}h \\
{[\mathrm{~m}]}\end{array}$ & $\begin{array}{c}B \\
{[\mathrm{~m}]}\end{array}$ & $\begin{array}{c}b_{4} \\
{[\mathrm{~m}]}\end{array}$ & $\begin{array}{c}b_{1} \\
{[\mathrm{~m}]}\end{array}$ & $\begin{array}{c}b_{3} \\
{[\mathrm{~m}]}\end{array}$ & $\begin{array}{c}s_{\mathrm{fp}} \\
{[-]}\end{array}$ & $\begin{array}{c}s_{\mathrm{mc}} \\
{[-]}\end{array}$ \\
\hline F1 & & & & & 4.1 & 4.100 & 0 & 1 \\
F2 & & & & & 2.25 & 2.250 & 1 & 1 \\
F3 & \multirow{2}{*}{1.027} & 0.15 & \multirow{2}{*}{1.8} & \multirow{2}{*}{1.5} & 0.75 & 0.750 & 1 & 1 \\
F6 & & & & & 2.25 & 0 & 1 & 1 \\
F8 & & & & & 2.25 & 2.250 & 1 & 0 \\
F10 & & & & & 2.25 & 2.250 & 1 & 2 \\
\hline K1 & & & & & 0.229 & 0.229 & & \\
K2 & \multirow{2}{*}{0.966} & 0.08 & 0.15 & 0.152 & 0.152 & 0.152 & 0 & 0 \\
K3 & & & & & 0.076 & 0.076 & 0 & \\
K4 & & & & & - & - & & \\
\hline
\end{tabular}

index of the measured and the computed flow rates as a measure of the model's performance (Nash and Sutcliffe, 1970).

The remaining three series, named F2, F8 and F10, plus four series from Knight and Demetriou (1983), named K1, $\mathrm{K} 2, \mathrm{~K} 3$ and $\mathrm{K} 4$, were used for validation (no.) 1, as reported in the next section. NS is given by

$\mathrm{NS}=\left[1-\frac{\sum_{j=1,2} \sum_{i=1, N_{J}} \sum_{K=1, M_{N_{J}}}\left(q_{i, j, k}^{\mathrm{obs}}-q_{i, j, k}^{\mathrm{sim}}\right)^{2}}{\sum_{j=1,2} \sum_{i=1, N_{J}} \sum_{K=1, M_{N_{J}}}\left(q_{i, j, k}^{\mathrm{obs}}-\overline{q_{i, j, k}^{\mathrm{obs}}}\right)^{2}}\right]$,

where $N_{j}$ is the number of series, $M_{N j}$ is the number of tests for each series, $q_{i, j, k}^{\mathrm{sim}}$ and $q_{i, j, k}^{\mathrm{obs}}$ are, respectively, the computed and the observed discharge $(j=1$ for the FCF series and $j=2$ for the Knight series; $i$ is the series index; and $K$ is the water depth index). $\overline{q_{i, j, k}^{\text {obs }}}$ is the average value of the measured discharges.

Both $\xi$ and $\beta$ parameters were calibrated by maximizing the NS index, computed using all the data of the four series used for calibration. See the NS versus $\xi$ and $\beta$ curves in Fig. 2a and b.

Calibration provides optimal $\xi$ and $\beta$ coefficients, respectively, equal to 0.08 and 9 . The authors will show in the next sensitivity analysis that even a one-digit approximation of the $\xi$ and $\beta$ coefficients provides a stable discharge estimation.

\subsection{Sensitivity analysis}

We carried out a discharge sensitivity analysis of both new methods using the computed $\xi=0.08$ and $\beta=9$ optimal values and the data of the F2 and K4 series. Sensitivities were 


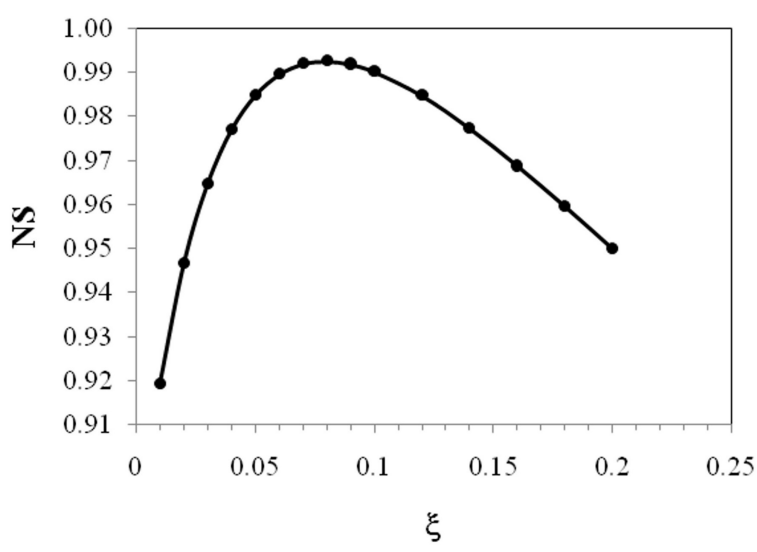

a)

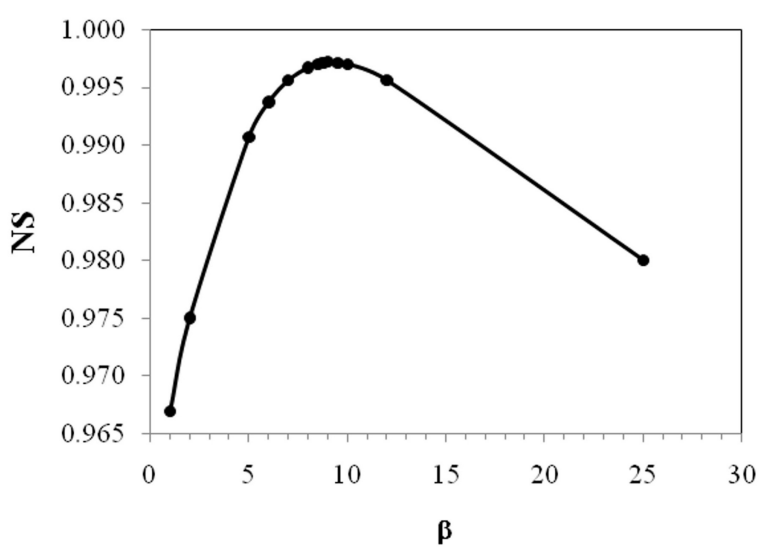

b)

Figure 2. NS versus $\xi$ and $\beta$ curves, respectively, for INCM (a) and LHRM (b) methods.

normalized in the following form:

$$
\begin{aligned}
I_{s} & =\frac{1}{q_{\mathrm{INCM}}} \frac{\Delta q}{\Delta \xi}, \\
L_{s} & =\frac{1}{q_{\mathrm{LHRM}}} \frac{\Delta q}{\Delta \beta},
\end{aligned}
$$

where $\Delta q$ is the difference between the discharges computed using two different $\beta$ and $\xi$ values. The assumed perturbations " $\Delta \beta$ " and " $\Delta \xi$ " are, respectively, $\Delta \beta=0.001 \beta$ and $\Delta \xi=0.001 \xi$.

The results of this analysis are shown in Table 2 for the F2 series, where $H$ is the water depth and $Q_{\text {meas }}$ the corresponding measured discharge.

They show very low sensitivity of both the INCM and LHRM results, such that a one-digit approximation of both model parameters $(\xi$ and $\beta$ ) should guarantee a computed discharge variability of less than $2 \%$.

The results of the sensitivity analysis, carried out for series $\mathrm{K} 4$ and shown in Table 2, are similar to the previous ones computed for $\mathrm{F} 2$ series.
Table 2. Sensitivities $I_{S}$ and $L_{S}$ computed in the $\mathrm{F} 2$ and $\mathrm{K} 4$ series

\begin{tabular}{|c|c|c|c|c|}
\hline & $\begin{array}{c}H \\
{[\mathrm{~m}]}\end{array}$ & $\underset{\left[\mathrm{m}^{3} \mathrm{~s}^{-1}\right]}{Q_{\text {meas }}}$ & $I_{S}$ & $L_{S}$ \\
\hline \multirow{7}{*}{ 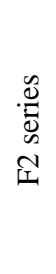 } & 156 & 0.212 & 0.2209 & 0.2402 \\
\hline & 0.169 & & & 0.2194 \\
\hline & 0.178 & & & 0.2044 \\
\hline & 0.187 & & 6 & 0.1777 \\
\hline & 0.198 & 0 & 1441 & 0.1584 \\
\hline & 0.214 & 0 & 5 & 0.1336 \\
\hline & 0.249 & 0.763 & 0.1267 & 0.1320 \\
\hline \multirow{6}{*}{ 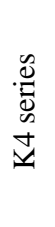 } & 0.0 & & & \\
\hline & 0.096 & 0.0 & 0.2052 & 0.2250 \\
\hline & 0.102 & סל & 0.1600 & 0.1709 \\
\hline & 0.114 & & & 0.1372 \\
\hline & 0.12 & & & 0.1208 \\
\hline & 0.154 & 0.029 & 0.0851 & 0.0866 \\
\hline
\end{tabular}
for the optimal parameter values.

\section{Validation criterion}

\subsection{Validation no. 1 - comparison with laboratory experimental data}

A first validation of the two methods was carried out by using the calibrated parameter values, the same Nash-Sutcliffe performance measure and all the available experimental series. The results were also compared with results of DCM and IDCM methods, the latter applied using the suggested $\alpha=0.02$ value and five subsections, each one corresponding to a different bottom slope in the lateral $y$ direction. The NS index for all data series is shown in Table 3.

The DCM results are always worse and are particularly bad for all the K series. The results of both the IDCM and INCM methods are very good for the two F series not used for calibration but are both poor for the K series. The LHRM method was always the best and also performed very well in the $\mathrm{K}$ series. The reason is probably that the $\mathrm{K}$ series tests have very low discharges and the constant $\alpha=0.02$, the coefficient adopted in the IDCM method, does not fit the size of the subsections, and Eq. (13) is not a good approximation of the mixing length $\alpha_{H}$ in Eq. (12) for low values of the water depth. In Fig. 3a and $b$ the NS curves obtained by using DCM, IDCM, INCM and LHRM, for series F2 and K4, are shown.

\subsection{Validation no. 2 - comparison with field data}

Although rating curves are available in different river sites around the world, field validation of the uniform flow formulas is not easy for at least two reasons.

1. The average friction factor $f$ and the related Manning coefficient are not known as in the lab case and the results of all the formulas need to be scaled according to 
Table 3. Nash-Sutcliffe efficiency for all (calibration and validation) experimental series.

\begin{tabular}{|c|c|c|c|c|c|}
\hline & Series & DCM & IDCM & INCM & LHRM \\
\hline \multirow{4}{*}{ 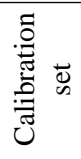 } & F1 & 0.7428 & 0.9807 & 0.9847 & 0.9999 \\
\hline & $\mathrm{F} 2$ & 0.6182 & 0.9923 & 0.9955 & 0.9965 \\
\hline & F3 & 0.7219 & 0.9744 & 0.9261 & 0.9915 \\
\hline & F6 & 0.7366 & 0.9733 & 0.9888 & 0.9955 \\
\hline \multirow{6}{*}{ 营 } & F8 & -0.0786 & 0.9881 & 0.9885 & 0.9964 \\
\hline & F10 & -0.0885 & 0.9965 & 0.9975 & 0.9978 \\
\hline & $\mathrm{K} 1$ & -14.490 & -0.7007 & -8.2942 & 0.9968 \\
\hline & $\mathrm{K} 2$ & -0.9801 & 0.3452 & -1.8348 & 0.9619 \\
\hline & K3 & 0.1762 & 0.6479 & -0.3944 & 0.9790 \\
\hline & K4 & 0.2878 & 0.888 & 0.3548 & 0.9958 \\
\hline
\end{tabular}
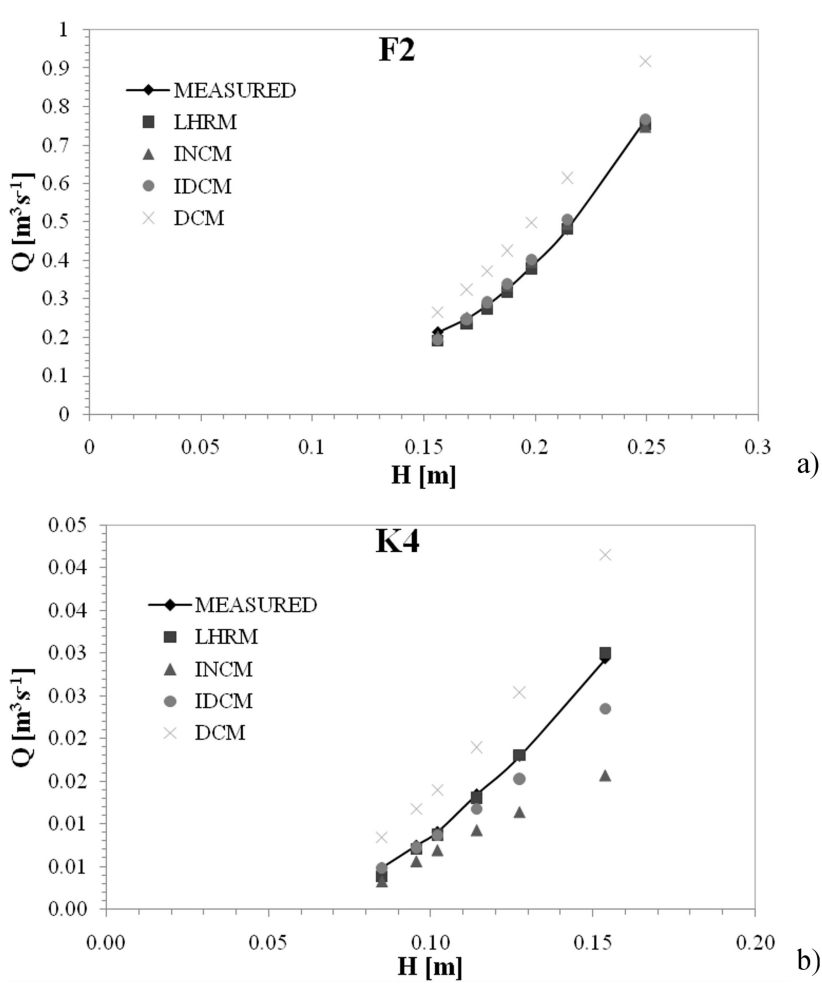

Figure 3. Estimated discharge values against HR Wallingford FCF measures for F2 (a) and K4 (b) series.

the Manning coefficient to be compared with the actually measured discharges.

2. River bed roughness does change, along with the Manning coefficient from one water stage to another (it usually increases along with the water level).

A possible way to circumvent the problem is to apply the compared methods in the context of a calibration problem, where both the average Manning coefficient and the discharge hydrograph are computed from the known level hydrographs measured in two different river cross sections (Perumal et al., 2007; Aricò et al., 2009). The authors solved the diffusive wave simulation problem using one known level hydrograph as the upstream boundary condition and the second one as the benchmark downstream hydrograph for the Manning coefficient calibration.

It is well known in the parameter estimation theory (Aster et al., 2012) that the uncertainty of the estimated parameters (in our case the roughness coefficient) grows quickly with the number of parameters, even if the matching between the measured and the estimated model variables (in our case the water stages in the downstream section) improves. The use of only one single parameter over all the computational domain is motivated by the need of getting a robust estimation of the Manning coefficient and of the corresponding discharge hydrograph.

Although the accuracy of the results is restricted by several modelling assumptions, a positive indication about the robustness of the simulation model (and the embedded relationship between the water depth and the uniform flow discharge) is given by (1) the match between the computed and the measured discharges in the upstream section, and (2) the compatibility of the estimated average Manning coefficient with the site environment.

The area of interest is located in the Alzette River basin (Grand Duchy of Luxembourg) between the gauged sections of Pfaffenthal and Lintgen (Fig. 4). The river reach length is about $19 \mathrm{~km}$, with a mean channel width of $\sim 30 \mathrm{~m}$ and an average depth of $\sim 4 \mathrm{~m}$. The river meanders in a relatively large and flat plain about $300 \mathrm{~m}$, with a mean slope of $\sim 0.08 \%$.

The methodology was applied to a river reach $13 \mathrm{~km}$ long, between two instrumented sections, Pfaffenthal (upstream section) and Hunsdorf (downstream section), in order to have no significant lateral inflow between the two sections.

Events of January 2003, January 2007 and January 2011 were analysed. For these events, stage records and reliable rating curves are available at the two gauging stations of Pfaffenthal and Hunsdorf. The main hydraulic characteristics of these events, namely duration $(\Delta t)$, peak water depth $\left(H_{\text {peak }}\right)$ and peak discharge $\left(q_{\text {peak }}\right)$, are shown in Table 4 .

In this area a topographical survey of 125 river cross sections was available. The hydrometric data were recorded every $15 \mathrm{~min}$. The performances of the discharge estimation procedures were compared by means of the Nash-Sutcliffe criterion.

The results of the INCM and LHRM methods were also compared with those of the DCM and IDCM methods, the latter applied by using $\alpha=0.02$ and an average subsection width equal to $7 \mathrm{~m}$. The computed average Manning coefficients $n_{\text {opt }}$, reported in Table 5, are all consistent with the site environment, although they attain very large values, according to DCM an IDCM, in the 2011 event.

The estimated and observed dimensionless water stages in the Hunsdorf gauged site for the 2003, 2007 and 2011 events are shown in Figs. 5-7.

Only the steepest part of the rising limb, located inside the coloured window of each figure, was used for calibration. 


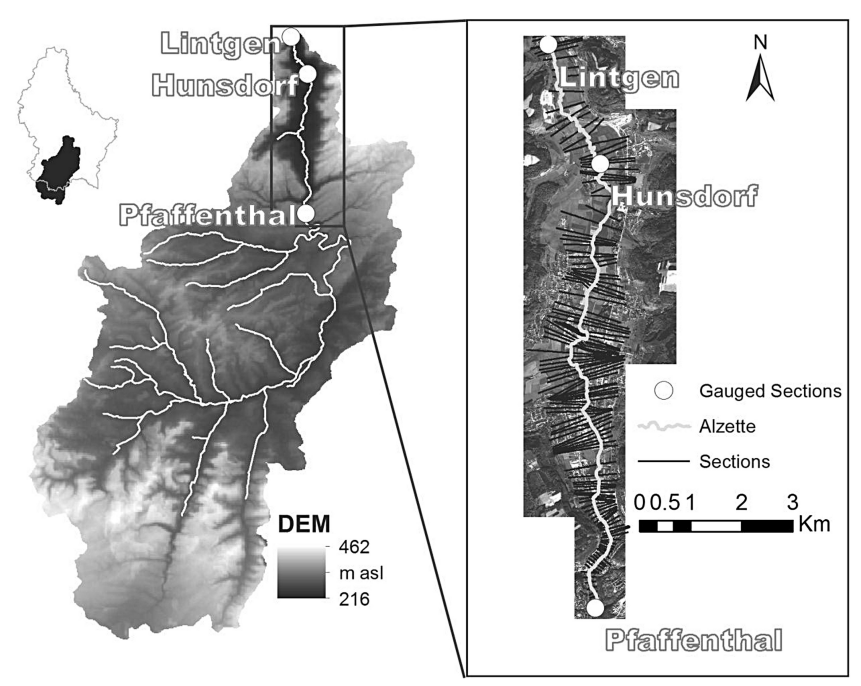

Figure 4. The Alzette study area.

Table 4. Main characteristics of the flood events at the Pfaffenthal and Hunsdorf gauged sites.

\begin{tabular}{lcccccc}
\hline Event & $\begin{array}{c}\Delta t \\
{[\mathrm{~h}]}\end{array}$ & \multicolumn{2}{c}{ Pfaffenthal } & & \multicolumn{2}{c}{ Hunsdorf } \\
\cline { 3 - 4 } \cline { 6 - 7 } & & $\begin{array}{c}H_{\text {peak }} \\
{[\mathrm{m}]}\end{array}$ & $\begin{array}{c}q_{\text {peak }} \\
{\left[\mathrm{m}^{3} \mathrm{~s}^{-1}\right]}\end{array}$ & & $\begin{array}{c}H_{\text {peak }} \\
{[\mathrm{m}]}\end{array}$ & $\begin{array}{c}Q_{\text {peak }} \\
{\left[\mathrm{m}^{3} \mathrm{~s}^{-1}\right]}\end{array}$ \\
\hline January 2003 & 380 & 3.42 & 70.98 & & 4.52 & 67.80 \\
January 2007 & 140 & 2.90 & 53.68 & & 4.06 & 57.17 \\
January 2011 & 336 & 3.81 & 84.85 & & 4.84 & 75.10 \\
\hline
\end{tabular}

Table 5. Optimum roughness coefficient, $n_{\mathrm{opt}}$, for the three flood events.

\begin{tabular}{lcccc}
\hline \multirow{2}{*}{ Event } & DCM & IDCM & INCM & LHRM \\
\cline { 2 - 5 } & \multicolumn{5}{c}{$n_{\text {opt }}$} \\
& \multicolumn{5}{c}{$\left[\mathrm{sm}^{-1 / 3}\right]$} \\
\hline January 2003 & 0.054 & 0.047 & 0.045 & 0.045 \\
January 2007 & 0.051 & 0.047 & 0.046 & 0.045 \\
January 2011 & 0.070 & 0.070 & 0.057 & 0.055 \\
\hline
\end{tabular}

The falling limb is not included, since it has a lower slope and is less sensitive to the Manning coefficient value.

A good match between recorded and simulated discharge hydrographs can be observed (Figs. 8-10) in the upstream gauged site for each event.

For all investigated events the Nash-Sutcliffe efficiency $\mathrm{NS}_{q}$ is greater than 0.90, as shown in Table 6.

The error obtained between measured and computed discharges, with all methods, is of the same order of magnitude as the discharge measurement error. Moreover, this measurement error is well known to be much larger around the peak flow, where the estimation error has a larger impact on the NS
Table 6. Nash-Sutcliffe efficiency of estimated discharge hydrographs for the analysed flood events.

\begin{tabular}{lrrrr}
\hline Event & DCM & IDCM & INCM & LHRM \\
\cline { 2 - 5 } & \multicolumn{4}{c}{$\begin{array}{c}\mathrm{NS}_{q} \\
{[-]}\end{array}$} \\
\hline January 2003 & 0.977 & 0.987 & 0.991 & 0.989 \\
January 2007 & 0.983 & 0.988 & 0.989 & 0.992 \\
January 2011 & 0.898 & 0.899 & 0.927 & 0.930 \\
\hline
\end{tabular}

coefficient. The NS coefficients computed with the LHRM and INCM methods are anyway a little better than the other two.

\subsection{Validation no. 3 - comparison with results of 3-D ANSYS CFX solver}

The vertically averaged velocities computed using DCM, IDCM, INCM and LHRM were compared with the results of the well-known ANSYS 3-D code, named CFX, which solves the RANS equations, applied to a prismatic reach with the irregular cross section measured at the Hunsdorf gauged section of the Alzette River. The length of the reach is about 4 times the top width of the section.

In the homogeneous multiphase model adopted by CFX, water and air are assumed to share the same dynamic fields of pressure, velocity and turbulence and water is assumed to be incompressible. CFX solves the conservation of mass and momentum equations, coupled with the air pressuredensity relationship and the global continuity equation in each node. We denote $\alpha_{1}, \rho_{1}, \mu_{1}$ and $\mathbf{U}_{1}$, respectively, as the volume fraction, the density, the viscosity and the timeaveraged value of the velocity vector for phase $l$ ( $l=\mathrm{w}$ (water), a (air)), i.e.

$$
\begin{aligned}
& \rho=\sum_{l=\mathrm{w}, \mathrm{a}} \alpha_{1} \rho_{1}, \\
& \mu=\sum_{l=\mathrm{w}, \mathrm{a}} \alpha_{1} \mu_{1},
\end{aligned}
$$

where $\rho$ and $\mu$ are the density and the viscosity of the "averaged" phase. The air density is assumed to be a function of the pressure $p$, according to the state equation:

$\rho_{\mathrm{a}}=\rho_{\mathrm{a}, 0} e^{\gamma\left(p-p_{0}\right)}$,

where the subindex 0 marks the reference state values and $\gamma$ is the air compressibility coefficient.

The governing equations are the following: (1) the mass conservation equation, (2) the Reynolds-averaged continuity equation of each phase and (3) the Reynolds-averaged momentum equations. Mass conservation implies

$$
\sum_{1=\mathrm{w}, \mathrm{a}} \alpha_{1}=1
$$




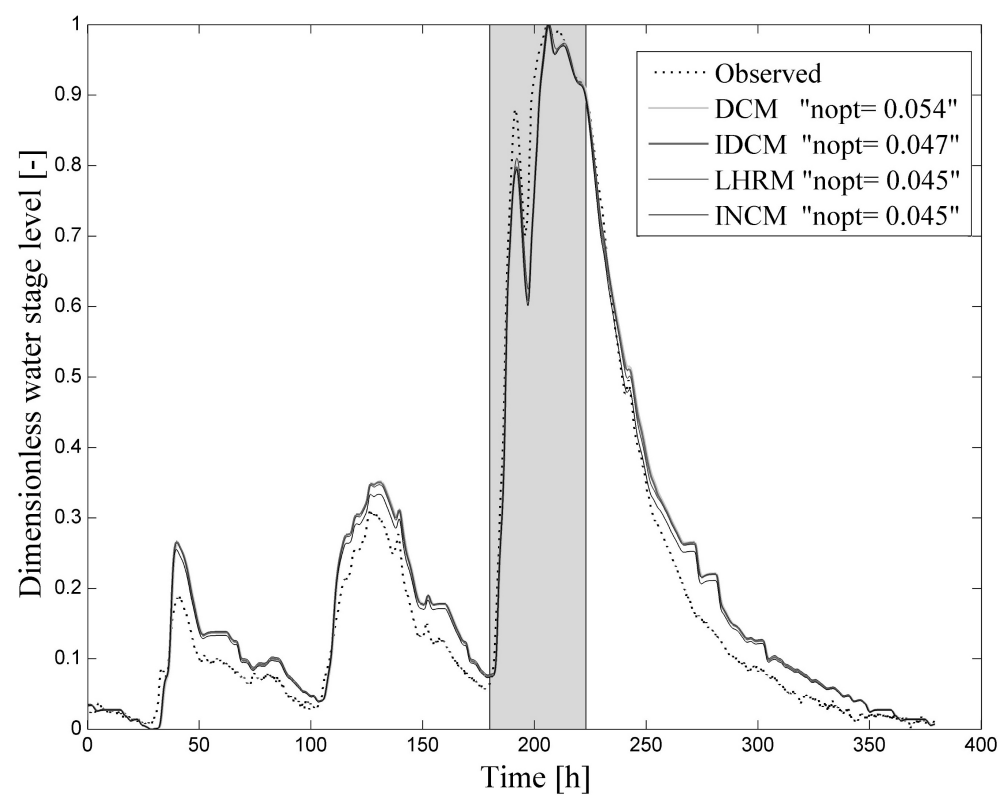

Figure 5. Observed and simulated stage hydrographs at the Hunsdorf gauged site in the event of January 2003.

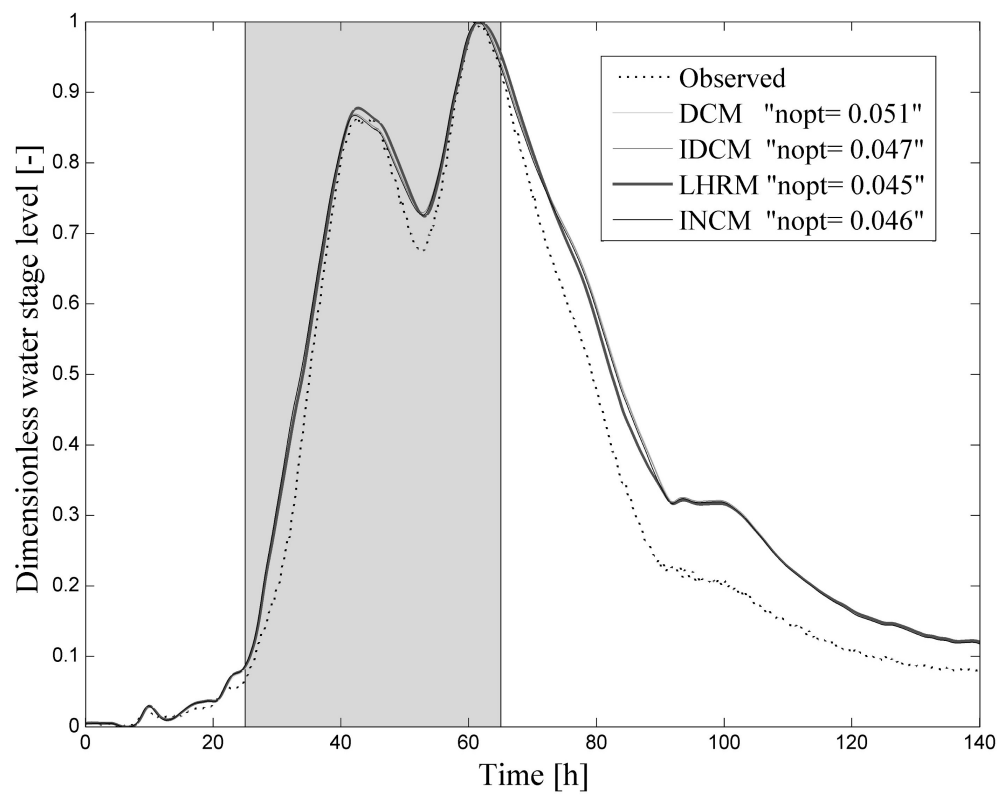

Figure 6. Observed and simulated stage hydrographs at the Hunsdorf gauged site in the event of January 2007.

The Reynolds-averaged continuity equation of each phase 1 can be written as

$\frac{\partial \rho_{1}}{\partial t}+\nabla \cdot\left(\rho_{1} \mathbf{U}\right)=S_{1}$

where $S_{1}$ is an external source term. The momentum equation instead refers to the "averaged" phase and is written as

$$
\begin{aligned}
\frac{\partial(\rho \mathbf{U})}{\partial t} & +\nabla \cdot(\rho \mathbf{U} \otimes \mathbf{U})-\nabla \cdot\left(\mu_{\mathrm{eff}}\left(\nabla \mathbf{U}+(\nabla \mathbf{U})^{T}\right)\right) \\
& +\nabla p^{\prime}=S_{\mathrm{M}},
\end{aligned}
$$

where $\otimes$ is the dyadic symbol, $S_{\mathrm{M}}$ is the momentum of the external source term $S$, and $\mu_{\text {eff }}$ is the effective viscosity accounting for turbulence and defined as

$\mu_{\mathrm{eff}}=\mu+\mu_{\mathrm{t}}$, 


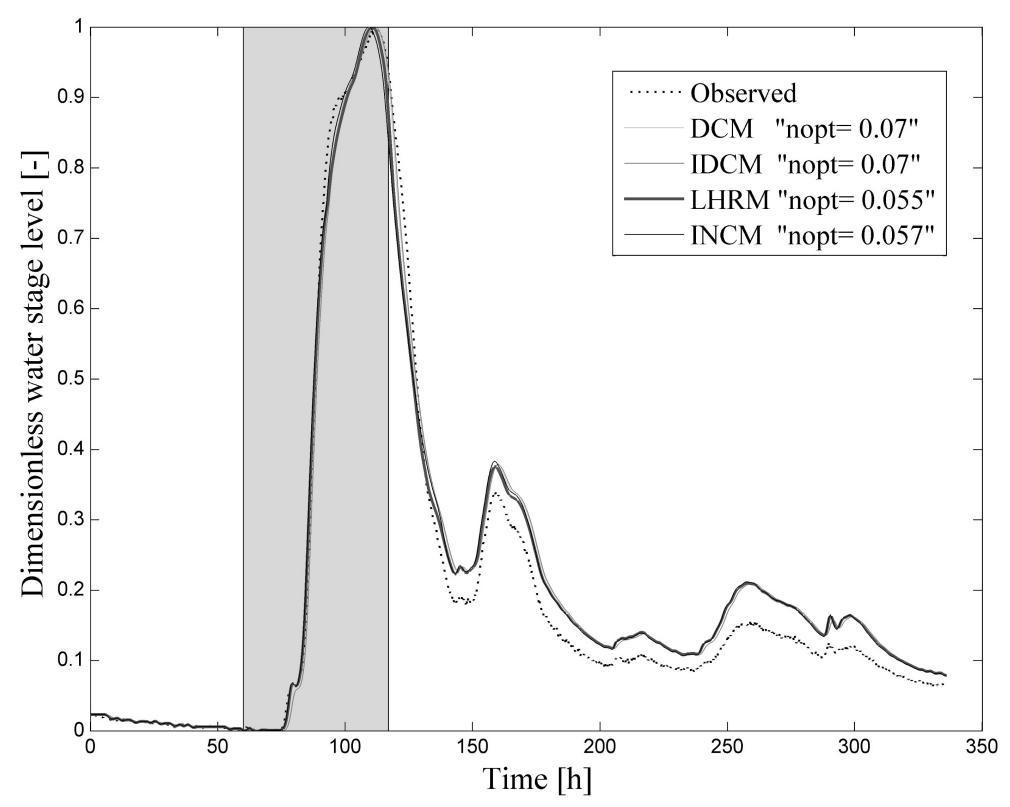

Figure 7. Observed and simulated stage hydrographs at the Hunsdorf gauged site in the event of January 2011.

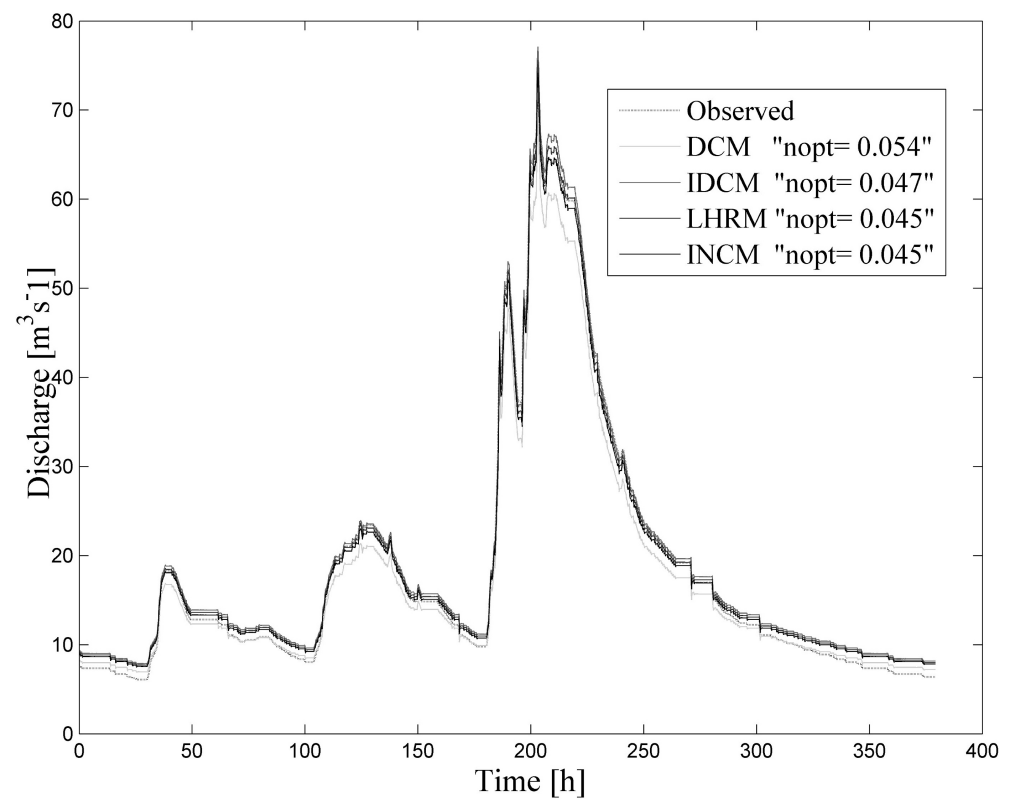

Figure 8. Observed and simulated discharge hydrographs at the Pfaffenthal gauged site in the event of January 2003.

where $\mu_{\mathrm{t}}$ is the turbulence viscosity and $p^{\prime}$ is the modified pressure, equal to

$p^{\prime}=p+\frac{2}{3} \rho k+\frac{2}{3} \mu_{\mathrm{eff}} \nabla \cdot \mathbf{U}$,

where $k$ is the turbulence kinetic energy, defined as the variance of the velocity fluctuations and $p$ is the pressure. Both phases share the same pressure $p$ and the same velocity $\mathbf{U}$.

To close the set of six scalar equations (Eqs. 23-25), we finally apply the $k-\varepsilon$ turbulence model implemented in the
CFX solver. The implemented turbulence model is a two equation model, including two extra transport equations to represent the turbulent properties of the flow.

Two-equation models account for history effects like convection and diffusion of turbulent energy. The first transported variable is turbulent kinetic energy, $k$; the second transported variable is the turbulent dissipation, $\varepsilon$. The " $k-$ $\varepsilon$ " model has been shown (Jones and Launder, 1972; Launder and Sharma, 1974) to be useful for free-shear layer flows with relatively small pressure gradients. Similarly, for wall- 


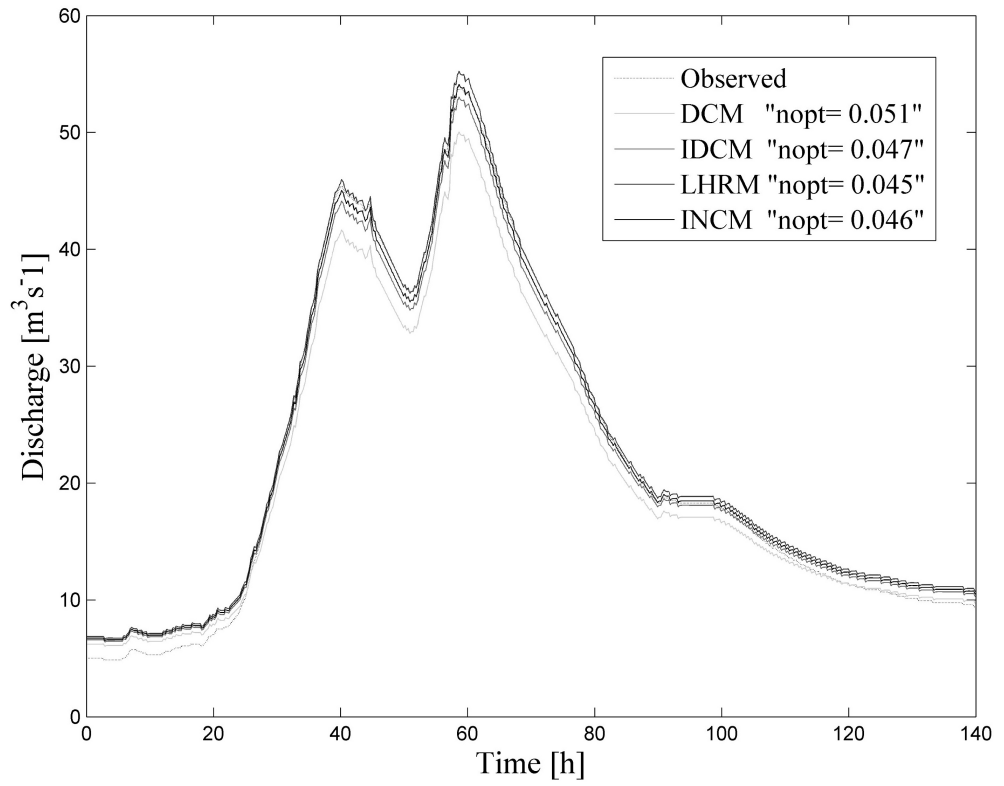

Figure 9. Observed and simulated discharge hydrographs at the Pfaffenthal gauged site in the event of January 2007.

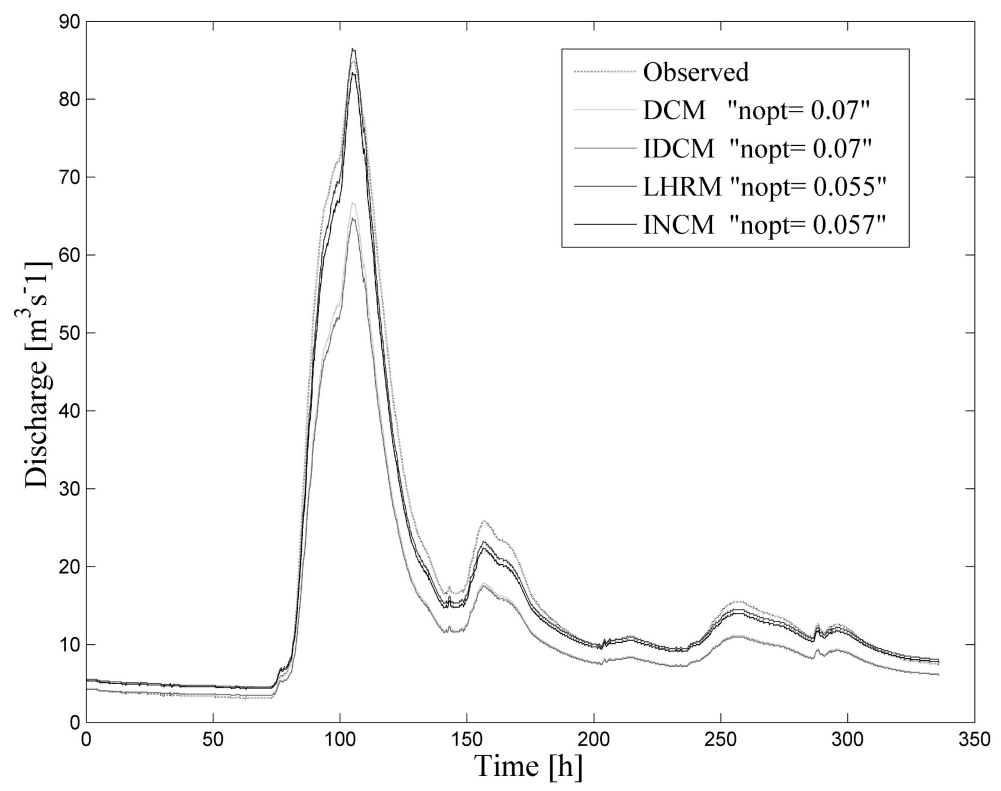

Figure 10. Observed and simulated discharge hydrographs at the Pfaffenthal gauged site in the event of January 2011.

bounded and internal flows, the model gives good results but only in cases where the mean pressure gradients are small.

The computational domain was divided using both tetrahedral and prismatic elements (Fig. 11). The prismatic elements were used to discretize the computational domain in the near-wall region over the river bottom and the boundary surfaces, where a boundary layer is present, while the tetrahedral elements were used to discretize the remaining domain. The number of elements and nodes in the mesh used for the specific case are of the order of, respectively, $4 \times 10^{6}$ and $20 \times 10^{6}$.

A section of the mesh is shown in Fig. 12. The quality of the mesh was verified by using a pre-processing procedure by ANSYS $^{\circledR}$ ICEM CFD $^{\mathrm{TM}}$ (Ansys Inc., 2006).

The six unknowns in each node are the pressure, the velocity components, and the volume fractions of the two phases. At each boundary node, three of the first four unknowns have to be specified. In the inlet section a constant velocity, normal to the section, is applied, and the pressure is left unknown. 
Table 7. Boundary conditions assigned in the CFX simulation.

\begin{tabular}{ll}
\hline Geometry face & Boundary condition \\
\hline Inlet & All velocity components \\
Outlet & Velocity direction and hydrostatic pressure distribution \\
Side walls & Opening \\
Top & Opening \\
Bottom & No-slip wall condition, with roughness given by equivalent granular size $d_{50}$ \\
\hline
\end{tabular}

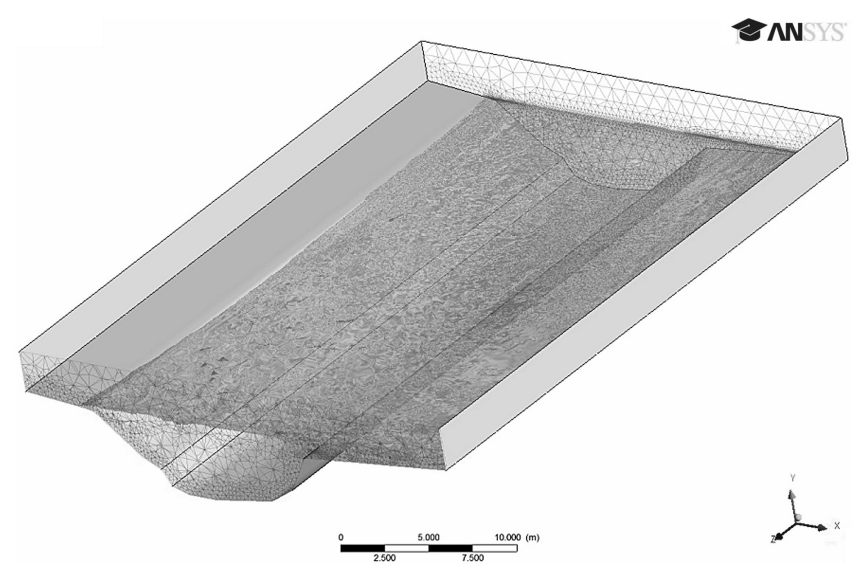

Figure 11. Computational domain of the reach of the Alzette River.

In the outlet section the hydrostatic distribution is given, the velocity is assumed to be still normal to the section and its norm is left unknown. All boundary conditions are reported in Table 7.

The opening condition means that that velocity direction is set normal to the surface, but its norm is left unknown and a negative (entering) flux of both air and water is allowed. Along open boundaries the water volume fraction is set equal to zero. The solution of the problem converges towards two extremes: nodes with zero water fraction, above the water level, and nodes with zero air fraction, below the water level.

On the bottom boundary, between the nodes with zero velocity and the turbulent flow, a boundary layer exists that would require the modelling of microscale irregularities. CFX allows using, inside the boundary layer, a velocity logarithmic law, according to an equivalent granular size. The relationship between the granular size and Manning's coefficient, according to Yen (1992), is given by

$d_{50}=\left(\frac{n}{0.0474}\right)^{6}$,

where $d_{50}$ is the average granular size to be given as the input in the CFX code.

Observe that the assumption of known and constant velocity directions in the inlet and outlet sections is a simplification of reality. A more appropriate boundary condition at the outlet section, not available in the CFX code, would have been given by zero velocity and turbulence gradients

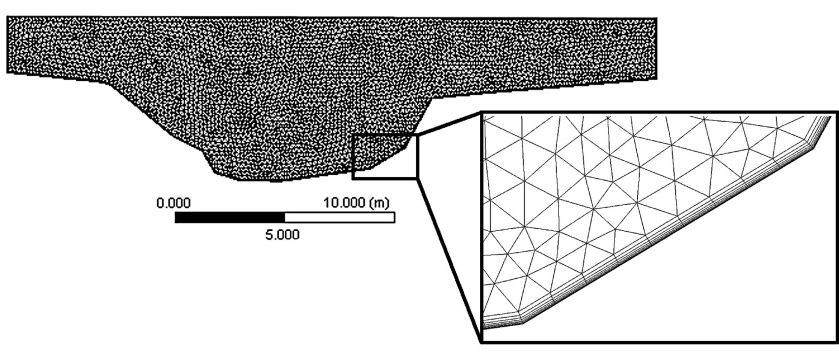

Figure 12. A mesh section along the inlet surface.

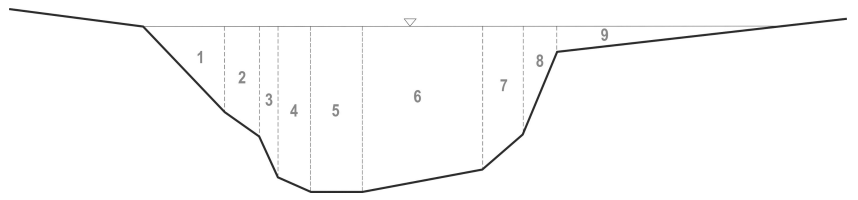

Figure 13. Hunsdorf river cross section: subsections used to compute the vertically averaged velocities.

(Rameshwaran et al., 2013). For this reason, a better reconstruction of the velocity field can be found in an intermediate section, where secondary currents with velocity components normal to the mean flow direction can be easily detected (Peters and Goldberg, 1989; Richardson and Thorne, 1998). See in Fig. 13 how the intermediate section was divided to compute the vertically averaged velocities in each segment section. These 3-D numerical simulations confirm that the momentum $\Gamma$, proportional to the derivative of the average tangent velocities and equivalent to the left-hand side of Eq. (2), cannot be set equal to zero if a rigorous reconstruction of the velocity field is sought after.

To compute the uniform flow discharge, for a given outlet section, the CFX code is run iteratively, each time with a different average longitudinal velocity in the inlet section, until the same water depth as in the outlet section is attained in the inlet section for steady-state conditions. Using the velocity distribution computed in the middle section along the steadystate computation as upstream boundary condition, transient analysis is carried on until pressure and velocity oscillations become periodic.

In order to test the achievement of the fully developed state within the first half of the modelled length, the authors plotted the vertical profiles of the streamwise velocity compo- 
Table 8. Simulated mean velocities in each segment section using 1-D hydraulic models with DCM, IDCM, INCM, LHRM and CFX, and the corresponding differences.

\begin{tabular}{|c|c|c|c|c|c|c|c|c|c|}
\hline \multirow[t]{2}{*}{ Subsection } & $u_{\mathrm{CFX}}$ & $u_{\mathrm{DCM}}$ & $u_{\mathrm{IDCM}}$ & $u_{\mathrm{INCM}}$ & $u_{\text {LHRM }}$ & $\Delta u_{\mathrm{DCM}}$ & $\Delta u_{\mathrm{IDCM}}$ & $\Delta u_{\mathrm{INCM}}$ & $\Delta u_{\text {LHRM }}$ \\
\hline & \multicolumn{5}{|c|}{$\left[\mathrm{ms}^{-1}\right]$} & \multicolumn{4}{|c|}{$[\%]$} \\
\hline 1 & 1.33 & 1.58 & 1.47 & 1.23 & 1.12 & 18.79 & 10.52 & -7.52 & -15.78 \\
\hline 2 & 1.37 & 1.42 & 1.4 & 1.36 & 1.38 & 3.65 & 2.19 & -0.73 & 0.73 \\
\hline 3 & 1.38 & 1.53 & 1.48 & 1.38 & 1.4 & 10.87 & 7.25 & 0 & 1.45 \\
\hline 4 & 1.47 & 1.64 & 1.6 & 1.56 & 1.57 & 11.56 & 8.84 & 6.13 & 6.80 \\
\hline 5 & 1.53 & 1.94 & 1.8 & 1.59 & 1.61 & 26.79 & 17.65 & 3.92 & 5.23 \\
\hline 6 & 1.57 & 2.01 & 1.81 & 1.6 & 1.68 & 28.02 & 15.29 & 1.91 & 7.00 \\
\hline 7 & 1.46 & 1.66 & 1.65 & 1.49 & 1.5 & 13.69 & 13.01 & 2.05 & 2.74 \\
\hline 8 & 1.42 & 1.48 & 1.46 & 1.44 & 1.43 & 4.22 & 2.82 & 1.40 & 0.70 \\
\hline 9 & 0.88 & 0.91 & 0.90 & 0.70 & 0.69 & 3.40 & 2.27 & -20.45 & -21.59 \\
\hline
\end{tabular}

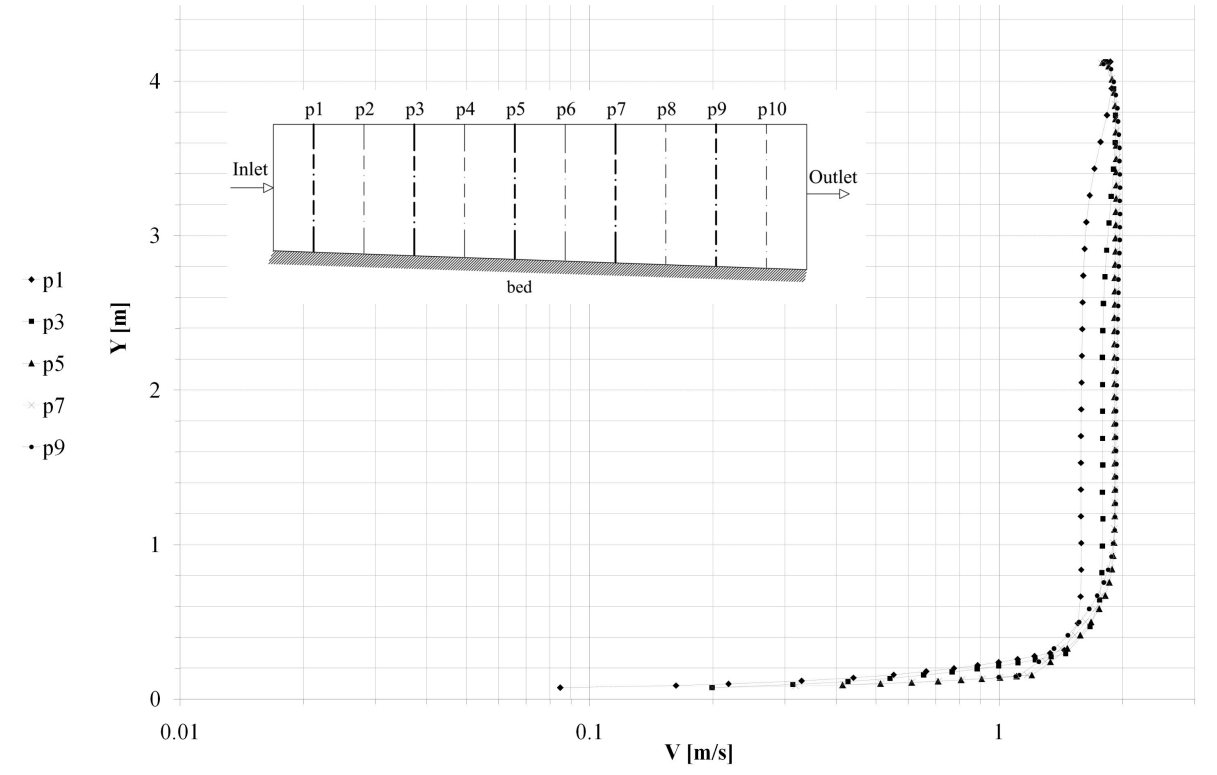

Figure 14. Streamwise vertical profile along the longitudinal axis of the mean channel.

nents for 10 verticals equally spaced along the longitudinal axis of the main channel. See in Fig. 14 the plot of four of them and their locations. The streamwise velocity evolves longitudinally and becomes almost completely self-similar starting from the vertical line in the middle section.

The stability of the results was finally checked against the variation of the length of the simulated channel. The dimensionless sensitivity of the discharge with respect to the channel length is equal to $0.2 \%$.

See in Table 8 the comparison between the vertically averaged state velocities, computed through the DCM, IDCM, INCM and LHRM formulas ( $\left.u_{\mathrm{DCM}}, u_{\mathrm{IDCM}}, u_{\mathrm{INCM}}, u_{\mathrm{LHRM}}\right)$ and through the CFX code $\left(u_{\mathrm{CFX}}\right)$. Table 8 also shows the relative difference, $\Delta u$, evaluated as

$\Delta u=\frac{u-u_{\mathrm{CFX}}}{u_{\mathrm{CFX}}} \cdot 100$
As shown in Table 8, both INCM and LHRM perform very well in this validation test instead of DCM, which clearly overestimates averaged velocities. In the central area of the section, the averaged velocities calculated by the INCM, LHRM and CFX code are quite close with a maximum difference of $\sim 7 \%$. By contrast, larger differences are evident close to the river bank, in segments 1 and 9, where INCM and LHRM underestimate the CFX values. These larger differences show the limit of using a 1-D code. Close to the bank the wall resistance is stronger and the velocity field is more sensitive to the turbulent exchange of energy with the central area of the section, where higher kinetic energy occurs. 


\section{Conclusions}

Two new methods computing the vertically averaged velocities along irregular sections have been presented. The first method, named INCM, develops from the original IDCM method and it is shown to perform better than the previous one, with the exception of lab tests with very small discharge values. The second one, named LHRM, has empirical bases and gives up the ambition of estimating turbulent stresses but has the following important advantages.

1. It relies on the use of only two parameters: the friction factor $f$ (or the corresponding Manning coefficient $n$ ) and a second parameter $\beta$, which on the basis of the available laboratory data, was estimated to be equal to 9.

2. The $\beta$ coefficient has a simple and clear physical meaning: the correlation distance, measured in water depth units, of the vertically averaged velocities between two different verticals of the river cross section.

3. The sensitivity of the results with respect to the model $\beta$ parameter was shown to be very low, and a one-digit approximation is sufficient to get a discharge variability of less than $2 \%$. A fully positive validation of the method was carried out using lab experimental data as well as field discharge and roughness data obtained by using the unsteady-state level analysis proposed by Aricò et al. (2009) and applied to the Alzette River in the Grand Duchy of Luxembourg.

4. Comparison between the results of the CFX 3-D turbulence model and the LHRM model shows a very good match between the two computed total discharges, although the vertically averaged velocities computed by the two models are quite different near to the banks of the river.
Moreover, the estimation of the velocity profiles in each of the considered subsections could be used in order to evaluate the vertical average velocity and thus the shear stresses at the boundary of the whole cross section. In fact, it is well known that bedload transport is directly related to the bed shear stress and that this is proportional in each point of the section to the second power of the vertically averaged velocity, according to Darcy and Weisbach (Ferguson, 2007):

$\tau_{0}=\rho U^{2} \frac{f}{8}$.

All the bedload formulas available in the literature compute the solid flux per unit width. For example, the popular Schoklitsch formula (Gyr and Hoyer, 2006) is

$q_{s}=\frac{2.5}{\rho_{s} / \rho} S^{\frac{3}{2}}\left(q-q_{\mathrm{c}}\right)$,

where $q$ and $q_{s}$ are, respectively, the liquid and the solid discharge per unit width. This implies that the information given by the mean velocity and by the cross-section geometry is not sufficient for a good estimation of the bedload in irregular sections. If Eq. (31) holds, the error in the bedload estimation is proportional to the error in the volumetric discharge discussed in the previous sections. 


\section{Appendix A}

Table A1. Notations.

\begin{tabular}{ll}
\hline$A_{i}$ & area of each subsection " $i$ " of a compound channel \\
$B$ & top width of compound channel \\
$b$ & main channel width at bottom \\
$f$ & friction factor \\
$g$ & gravity acceleration \\
$H$ & total depth of a compound channel \\
$n_{\mathrm{mc}}, n_{\mathrm{fp}}$ & Manning's roughness coefficients for the main channel and floodplain, respectively \\
$P_{i}$ & wetted perimeter of each subsection " $i$ " of a compound channel \\
$Q_{\mathrm{meas}}$ & measured discharge \\
$R_{i}$ & hydraulic radius of each subsection " $i$ " of a compound channel \\
$S_{0}$ & longitudinal channel bed slope \\
$S_{f}$ & energy slope \\
$\tau$ & turbulent stress \\
$\varepsilon$ & turbulent dissipation \\
$\rho$ & fluid density \\
$\mu$ & fluid viscosity \\
$\alpha$ & IDCM interface coefficient \\
$\beta$ & LHRM coefficient \\
$\xi$ & INCM coefficient \\
\hline
\end{tabular}


Acknowledgements. The authors wish to express their gratitude to the Administration de la gestion de l'eau of the Grand-Duché de Luxembourg and the Centre de Recherche Public Gabriel Lippmann for providing hydrometric and topographical data of the Alzette River.

Edited by: R. Moussa

\section{References}

Abril, J. B. and Knight, D. W.: Stage-discharge prediction for rivers in flood applying a depth-averaged model, J. Hydraul. Res., 42, 616-629, 2004.

Ackers, P.: Flow formulae for straight two-stage channels, J. Hydraul. Res., 31, 509-531, 1993.

Ansys Inc.: ANSYS CFX Reference guide, Canonsburg, Pennsylvania, USA, 2006.

Aricò, C., Nasello, C., and Tucciarelli, T.: Using unsteady water level data to estimate channel roughness and discharge hydrograph, Adv. Water Resour., 32, 1223-1240, 2009.

Aster, C., Borchers, B., and Clifford, H.: Parameter Estimation and Inverse Problems, Elsevier, Academic Press, USA, 2012.

Bousmar, D. and Zech, Y.: Momentum transfer for practical flow computation in compound channels, J. Hydraul. Eng., 125, 696706, 1999.

Cao, Z., Meng, J., Pender, G., and Wallis, S.: Flow resistance and momentum flux in compound open channels, J. Hydraul. Eng., 132, 1272-1282, 2006.

Chow, V. T.: Open Channel Hydraulics, McGraw-Hill, New York, 1959.

Ferguson, R.: Flow resistance equations for gravel and boulder-bed streams, Water Resour. Res., 43, W05427, doi:10.1029/2006WR005422, 2007.

Gyr, A. and Hoyer, K.: Sediment Transport A geophysical Phenomenon, Springer, A. A Dordrecht, The Netherlands, 30-31, 2006.

HEC-RAS, River Analysis System, Hydraulic Reference Manual, US Army Corps of Engineers, Hydrologic Engineering Center, Davis, CA, 411 pp., 2010.

Herschel, C.: On the origin of the Chezy formula, Journal Association of Engineering Societies, 18, 363-368, 1897.

Huthoff, F., Roos, P. C., Augustijn, D. C. M., and Hulscher, S. J. M. H.: Interacting divided channel method for compound channel flow, J. Hydraul. Eng., 134, 1158-1165, 2008.

Jones, W. P. and Launder, B. E.: The prediction of laminarization with a two-equation model of turbulence, Int. J. Heat Mass Tran., 15, 301-314, 1972.

Knight, D. W. and Abril, B.: Refined calibration of a depth averaged model for turbulent flow in a compound channel, P. I. Civil Eng.Water, 118, 151-159, 1996.

Knight, D. W. and Demetriou, J. D.: Flood plain and main channel flow interaction, J. Hydraul. Eng., 109, 1073-1092, 1983.

Knight, D. W. and Hamed, M. E.: Boundary shear in symmetrical compound channels, J. Hydraul. Eng., 110, 1412-1430, 1984.

Knight, D. W. and Sellin, R. H. J.: The SERC flood channel facility, J. Inst. Water Env. Man., 1, 198-204, 1987.

Knight, D. W. and Shiono, K.: River channel and floodplain hydraulics, in: Floodplain Processes, edited by: Anderson, M. G.,
Walling, D. E., and Bates, P. D., Wiley, New York, Chapter 5, 139-181, 1996.

Lambert, M. F. and Sellin, R. H. J.: Discharge prediction in straight compound channels using the mixing length concept, J. Hydraul. Res., 34, 381-394, 1996.

Launder, B. E. and Sharma, B. I.: Application of the energy dissipation model of turbulence to the calculation of flow near a spinning disc, Lett. Heat Mass Trans., 1, 131-138, 1974.

Liao, H. and Knight, D. W.: Analytic stage-discharge formulas for flow in straight prismatic channels, J. Hydraul. Eng., 133, 11111122, 2007.

Lyness, J. F., Myers, W. R. C., Cassells, J. B. C., and O'Sullivan, J. J.: The influence of planform on flow resistance in mobile bed compound channels, P. I. Civil Eng.-Water, 148, 5-14, 2001.

MIKE11: A Modelling System for Rivers and Channels, Reference Manual, DHI, Denmark, 524 pp., 2009.

Moreta, P. J. M. and Martin-Vide, J. P.: Apparent friction coefficient in straight compound channels, J. Hydraul. Res., 48, 169-177, 2010.

Myers, W. R. C. and Brennan, E. K.: Flow resistance in compound channels, J. Hydraul. Res., 28, 141-155, 1990.

Nash, J. E. and Sutcliffe, J. V.: River flow forecasting through conceptual models, Part I - A discussion of principles, J. Hydrol., 10, 282-290, 1970.

Omran, M. and Knight, D. W.: Modelling secondary cells and sediment transport in rectangular channels, J. Hydraul. Res., 48, 205 212, 2010.

Peters, J. J. and Goldberg, A.: Flow data in large alluvial channels, in: Computational Modeling and Experimental methods in $\mathrm{Hy}$ draulics, edited by: Maksimovic, C. and Radojkovic, M., Elsevier, London, 77-86, 1989.

Perumal, M., Moramarco, T., Sahoo, B., and Barbetta, S. A methodology for discharge estimation and rating curve development at ungauged river sites, Water Resour. Res., 43, W02412, doi:10.1029/2005WR004609, 2007.

Rameshwaran, P. and Shiono, K.: Quasi two-dimensional model for straight overbank flows through emergent vegetation on floodplains, J. Hydraul. Res., 45, 302-315, 2007.

Rameshwaran, P., Naden, P., Wilson, C., Malki, R., Shukla, D., and Shiono, K.: Inter-comparison and validation of computational fluid dynamics codes in two-stage meandering channel flows, Appl. Math. Model., 37, 8652-8672, doi:10.1016/j.apm.2013.07.016, 2013.

Rhodes, D. G. and Knight, D. W.: Velocity and boundary shear in a wide compound duct, J. Hydraul. Res., 32, 743-764, 1994.

Richardson, R. W. and Thorne, C. R.: Secondary currents around Braid Bar in Brahmaputra River, Bangladesh, J. Hydraul. Eng., 124, 325-328, 1998.

Sellin, R. H. J.: A laboratory investigation into the interaction between the flow in the channel of a river and that over its flood plain, La Houille Blanche, 7, 793-801, 1964.

Shiono, K. and Knight, D. W.: Turbulent open-channel flows with variable depth across the channel, J. Fluid Mech., 222, 617-646, 1991.

Shiono, K., Al-Romaih, J. S., and Knight, D. W.: Stage-discharge assessment in compound meandering channels, J. Hydraul. Eng., 125, 66-77, 1999.

Stephenson, D. and Kolovopoulos, P.: Effects of momentum transfer in compound channels, J. Hydraul. Eng., 116, 1512-1522, 1990. 
Tang, X. and Knight, D. W.: Lateral depth-averaged velocity distributions and bed shear in rectangular compound channels, J. Hydraul. Eng., 134, 1337-1342, 2008.

van Prooijen, B. C., Battjes, J. A., and Uijttewaal, W. S. J.: Momentum exchange in straight uniform compound channel flow, $\mathrm{J}$. Hydraul. Eng., 131, 175-183, 2005.

Wilcox, D. C., Turbulence Modeling for CFD, 3rd edition, DCW Industries, Inc., La Canada CA, 2006.
Wormleaton, P. R. and Hadjipanos, P.: Flow distribution in compound channels, J. Hydraul. Eng., 111, 357-361, 1985.

Wormleaton, P. R., Allen, J., and Hadjipanos, P.: Discharge assessment in compound channel flow, J. Hydraul. Div., 108, 975-994, 1982.

Yen, B. C.: The Manning formula in context, in: Channel Flow Resistance: Centennial of Manning's Formula, Water Resources Publications, Littleton, Colorado, USA, 33-285, 1992. 